\title{
Analysis of the relationship between fasting serum uric acid and the insulin sensitivity index in a population-based sample of 380 young healthy Caucasians
}

\author{
Jesper O Clausen ${ }^{1,2}$, Knut Borch-Johnsen ${ }^{1,2}$, Hans Ibsen $^{1}$ and Oluf Pedersen ${ }^{2}$ \\ ${ }^{1}$ Copenhagen County, Centre of Preventive Medicine, Medical Department C, Glostrup University Hospital, Denmark and ${ }^{2}$ Steno Diabetes Centre, \\ Gentofte, Copenhagen, Denmark
}

(Correspondence should be addressed to J O Clausen, Johannevej 12, DK-2920 Charlottenlund, Denmark)

\begin{abstract}
Aim: To determine whether fasting serum uric acid is associated with the insulin sensitivity index or with other anthropometric, metabolic or environmental features of the insulin resistance syndrome in a population-based sample of young healthy Caucasians.

Methods: The protocol included 380 unrelated Caucasian subjects (age 18-32 years) who had their insulin sensitivity index and glucose effectiveness measured during a combined intravenous glucose $(0.3 \mathrm{~g} / \mathrm{kg}$ body weight $)$ and tolbutamide $(3 \mathrm{mg} / \mathrm{kg}$ body weight) tolerance test. A number of anthropometric and biochemical tests, including the level of fasting serum uric acid, were carried out. Results: In univariate analyses the concentration of fasting serum uric acid was negatively correlated to the insulin sensitivity index in both men $\left(r^{2}=-0.25, P=0.001\right)$ and women $\left(r^{2}=-0.25\right.$, $P<0.001)$. In multivariate analysis controlling for age, gender, body mass index, waist to hip ratio, maximal aerobic capacity, fasting serum triglyceride and creatinine, daily intake of alcohol, smoking, use of oral contraceptives, and disposition for non-insulin dependent diabetes mellitus, the insulin sensitivity index was not significantly associated with fasting serum uric acid. However, $51 \%$ of the variation in the fasting serum uric acid level could be explained, and fasting serum triglyceride was the most important determinant of fasting serum uric acid.

Conclusion: The major determinant of the fasting serum uric acid level in young healthy Caucasians is the fasting concentration of serum triglyceride, which has been shown to be a biochemical feature of the insulin resistance syndrome. Thus, hyperuricaemia appears to be an indirect part of the insulin resistance syndrome through its association with fasting hypertriglyceridaemia.
\end{abstract}

European Journal of Endocrinology 138 63-69

\section{Introduction}

The clustering in some individuals of impaired glucose tolerance, obesity, hypertension, and dyslipidaemia, all states which separately or in combination are characterized by reduced whole body insulin sensitivity, has been designated the insulin resistance syndrome (1). Low insulin sensitivity, defined as a high fasting or stimulated serum insulin value, has in some studies been found to predict subsequent cardiovascular disease, especially in men (2-9). Hyperuricaemia is also associated with obesity, hypertriglyceridaemia, impaired glucose tolerance, and hypertension (10-13). Moreover, several epidemiological studies have shown that increased fasting serum levels of uric acid is a risk factor for cardiovascular disease (14-16). The resemblance of the insulin resistance syndrome and hyperuricaemia has led to the suggestion that hyperuricaemia is a part of the insulin resistance syndrome (17-20).

The relationship between insulin sensitivity and fasting serum uric acid has not been examined in a populationbased sample of young subjects. Young healthy subjects are an ideal population to examine relationships between insulin sensitivity and variables in the insulin resistance syndrome, because in young healthy subjects insulin resistance-associated variables are not influenced by chronic diseases. The objectives of the present investigation were to evaluate whether hyperuricaemia correlates with a low insulin sensitivity index and the cluster of metabolic, anthropometric and environmental features closely associated with impaired insulin sensitivity in a population-based sample of young, healthy Caucasians. Furthermore, we wanted to study whether impaired insulin sensitivity or another component of the insulin resistance syndrome was independently associated with elevated levels of fasting serum uric acid.

\section{Subjects and methods}

\section{Subjects}

The present investigation was population based. The study participants were randomly recruited from a 
population of young individuals aged 18-32 years, who in 1979 and again in 1984/85 as children had participated in blood pressure surveys in a representative and specified part of Copenhagen city (21-23). All were Danish Caucasians by self-identification. The present examination took place in 1992 and 1993. All subjects from the initial cohort except one could be traced in the Danish Central Population Register $(n=1389)$. Subjects with insulin dependent diabetes mellitus, pregnant women, and subjects now living in the western part of Denmark or abroad were excluded from the study $(n=89)$. A random sample of unrelated subjects in the initial cohort was invited to participate in the present examination. The participation rate was $56 \%$ (380 of 697) and altogether 380 non-related individuals were included in the protocol (Table 1). Two lean subjects (body mass index (BMI) $<25 \mathrm{~kg} / \mathrm{m}^{2}$ ) were treated with inhalation of $\beta-2$ adrenergic agonists for their asthma and 50 females were on oral contraceptives. No study participants were taking any other drugs on a regular basis and all were asked not to take aspirin, paracetamol or non-steroidal anti-inflammatory drugs on the day of examination. Parental history of noninsulin dependent diabetes mellitus (NIDDM) was considered present if the subjects reported that one or both of their parents had NIDDM. Informed consent was obtained from all study participants. The study protocol was approved by the Ethical Committee of Copenhagen and was in accordance with the Helsinki Declaration.

\section{Anthropometric measurements, alcohol consumption and smoking}

Waist circumference was measured midway between the lower rib margin and the iliac crest in the horizontal plane. Hip circumference was measured at the point yielding the maximum circumference over the buttocks. The variables were measured with the individuals in an upright position and taken to the nearest $0.5 \mathrm{~cm}$. Height was measured to the nearest $0.5 \mathrm{~cm}$ with the subjects standing without shoes, the heels together and the head in the horizontal plane. Body weight was measured to the nearest $0.1 \mathrm{~kg}$, subjects wearing only light clothes. BMI was calculated as weight divided by squared height $\left(\mathrm{kg} / \mathrm{m}^{2}\right)$. Maximal aerobic capacity $\left(\mathrm{VO}_{2} \max \right)$ was measured by means of a submaximal bicycle exercise test as described by Åstrand \& Ryhning (24).

Blood pressure was determined by means of a London School of Hygiene sphygmomanometer (25), making the readings unbiased, as the scale is not visible during deflation of the cuff. Recording of blood pressure took place between 1200 and $1400 \mathrm{~h}$, when the subjects had participated in the study for a minimum of $4 \mathrm{~h}$ and were in a relaxed state and after they had eaten lunch. All blood pressure measurements were done in the supine position by the same nurse. Systolic and diastolic blood pressure measurements (read at the disappearance of the fifth Korotkoff sound) were recorded. The standard blood pressure cuff was $12 \times 35 \mathrm{~cm}$. In subjects having an upper arm circumference of more than $35 \mathrm{~cm}$, a cuff measuring $15 \times 43 \mathrm{~cm}$ was used, and in subjects having an upper arm circumference of less than $20 \mathrm{~cm}$, a cuff measuring $9 \times 25 \mathrm{~cm}$ was used.

The total daily alcohol consumption was calculated from questionnaire items about average alcohol consumption. Intakes of beer, wine, and spirits were reported separately. Most of the alcohol consumed was in beer. One drink corresponded to $12 \mathrm{~g}$ ethanol. Smoking was assessed by a questionnaire.

Table 1 Clinical and biochemical characteristics (means \pm S.D.) of men and women in the population-based sample of 380 healthy Danish Caucasians.

\begin{tabular}{|c|c|c|c|}
\hline & Men & Women & $\begin{array}{c}\text { Significance level: } \\
\text { men versus women }(P)\end{array}$ \\
\hline Number & 186 & 194 & - \\
\hline Age (years) & $25.5(3.5)$ & $25.0(3.5)$ & - \\
\hline $\mathrm{BMI}\left(\mathrm{kg} / \mathrm{m}^{2}\right)$ & $24.2(3.5)$ & $23.0(3.9)$ & 0.0001 \\
\hline Waist to hip ratio & $0.86(0.05)$ & $0.77(0.06)$ & $<0.0001$ \\
\hline Systolic blood pressure (mmHg) & $121(12)$ & $109(9)$ & $<0.0001$ \\
\hline Diastolic blood pressure (mmHg) & $67(8)$ & $62(8)$ & $<0.0001$ \\
\hline $\mathrm{VO}_{2} \max \left(\mathrm{ml} \mathrm{O}_{2} /(\mathrm{kg} \times \min )\right)$ & $44(9)$ & $38(8)$ & $<0.0001$ \\
\hline Alcohol consumption (g/day) & $15(15)$ & $6(7)$ & $<0.0001$ \\
\hline Smoking (\%) & 41 & 49 & 0.12 \\
\hline Fasting serum uric acid* $(\mu \mathrm{mol} / \mathrm{l})$ & $333(66)$ & $236(54)$ & $<0.0001$ \\
\hline Fasting serum triglyceride (mmol/l) & $1.2(0.9)$ & $1.0(0.5)$ & 0.0006 \\
\hline Fasting plasma glucose (mmol/l) & $5.2(0.5)$ & $4.8(0.4)$ & $<0.0001$ \\
\hline Fasting serum creatinine $(\mu \mathrm{mol} / \mathrm{l})$ & $93(11)$ & $82(14)$ & $<0.0001$ \\
\hline Disposition for NIDDM (\%) & 6.6 & 8.3 & 0.53 \\
\hline Insulin sensitivity index $\left(10^{-5} \times(\min \times \mathrm{pmol} / \mathrm{l})^{-1}\right)$ & $15.2(8.9)$ & $15.2(9.7)$ & 0.68 \\
\hline Glucose effectiveness $\left(10^{-2} \times \min ^{-1}\right)$ & $2.0(0.6)$ & $2.3(0.6)$ & $<0.0001$ \\
\hline Glucose disappearance constant $\left(\mathrm{min}^{-1}\right)$ & $2.1(0.9)$ & $2.6(1.2)$ & 0.0001 \\
\hline
\end{tabular}

* Four men and one woman did not have uric acid measured due to lack of serum. 


\section{Biochemical studies}

After $12 \mathrm{~h}$ overnight fasting venous blood samples were drawn in the morning. Serum levels of triglyceride, uric acid and creatinine were analysed using standardized methods. The concentration of insulin was determined by ELISA with a narrow specificity excluding des[31,32]- and intact proinsulin, employing the Dako insulin kit with overnight incubation (Code No K6219 Dako Diagnostics Ltd, Ely, UK) (26).

\section{Measurements of the insulin sensitivity index and glucose effectiveness}

Each subject underwent an intravenous glucose tolerance test (IVGTT) after an overnight fasting period of $12 \mathrm{~h}$. After insertion of a venous cannula into the antecubital vein all subjects rested in a quiet room for at least $20 \mathrm{~min}$. Baseline values of serum insulin and plasma glucose were taken in duplicate at $5 \mathrm{~min}$ intervals. Glucose was injected i.v. in the contralateral antecubital vein over a period of $60 \mathrm{~s}(0.3 \mathrm{~g} / \mathrm{kg}$ body weight of $50 \%$ glucose). At $20 \mathrm{~min}$ following the end of the glucose injection, a bolus of $3 \mathrm{mg}$ tolbutamide $/ \mathrm{kg}$ body weight (Rastinon, Hoechst, Germany) was injected during $5 \mathrm{~s}$ to elicit a secondary pancreatic $\beta$-cell response. Venous blood was sampled at $2,4,8,19$, $22,30,40,50,70,90$ and $180 \mathrm{~min}$, timed from the end of the glucose injection, for measurements of plasma glucose and serum insulin. All the IVGTTs were done by the same investigator. The insulin sensitivity index and glucose effectiveness were calculated using the Bergman MINMOD computer program developed specifically for the combined intravenous glucose and tolbutamide tolerance test (27-30). The insulin sensitivity index represents the increase in net fractional glucose clearance rate per unit change in plasma insulin concentration following the intravenous glucose load. Glucose effectiveness represents the net fractional glucose clearance rate simply due to the increase in glucose itself without any increase in insulin concentration above baseline. Importantly, both the insulin sensitivity index and glucose effectiveness involve an inhibition of hepatic glucose output and an acceleration of peripheral glucose uptake due to insulin and glucose, respectively $(27,28)$. Furthermore, glucose effectiveness includes a contribution mediated by the preexisting basal insulin status and a contribution from hyperglycaemia per se without insulin. The tolbutamideboosted protocol for frequently sampled IVGTT with minimal model analysis has been validated in normal subjects against the euglycaemic, hyperinsulinaemic clamp $(28,31,32)$.

\section{Statistics}

Differences of continuous variables between the groups were tested by the Mann-Whitney test. Differences of categorical variables were tested using chi-square.
Spearman correlation coefficients between fasting serum uric acid and the insulin sensitivity index, glucose effectiveness, age, gender, BMI, waist to hip ratio, $\mathrm{VO}_{2} \mathrm{max}$, fasting serum triglyceride and creatinine, systolic and diastolic blood pressure, daily intake of alcohol, smoking, disposition of NIDDM, and use of oral contraception, were calculated in the whole population and stratified in men and women as appropriate. Multiple linear regression analysis was used to elucidate any independent effect of any variable on fasting serum uric acid. Interaction variables between gender and all continuous explanatory variables (the insulin sensitivity index, age, gender, BMI, waist to hip ratio, $\mathrm{VO}_{2}$ max, fasting serum triglyceride and creatinine and daily intake of alcohol) were constructed and included in a multiple regression analysis. All interaction variables were without significant effect and were excluded in the final multiple regression analysis. Statistical Package of Social Science (SPSS) for Windows, version 6.01, was used for statistical analyses. A $P$ value $<0.05$ (two-tailed) was considered significant.

\section{Results}

Fasting serum uric acid was significantly higher in men than in women (Table 1). As reported previously (23), BMI, waist to hip ratio and fasting serum triglyceride were higher in men compared with women, whereas glucose effectiveness was significantly lower. The insulin sensitivity index did not differ between men and women despite the higher fasting serum uric acid in men compared with women (23).

In the univariate analyses in men the strongest associations to fasting serum uric acid were found with BMI and fasting serum triglyceride (Table 2). The strongest associations in women with fasting serum uric acid were found with BMI and the insulin sensitivity index. In women the associations with fasting serum uric acid were weaker than in men. In both men and women, significantly negative associations with fasting serum uric acid were found regarding the insulin sensitivity index and the maximal aerobic capacity (Table 2). No significant association was found between fasting serum uric acid and glucose effectiveness in either men or women (Table 2).

In the multiple regression analysis including the insulin sensitivity index, age, gender, BMI, waist to hip ratio, $\mathrm{VO}_{2} \mathrm{max}$, fasting serum triglyceride and creatinine, daily intake of alcohol, smoking, use of oral contraceptives, and disposition for NIDDM as explanatory variables, fasting serum uric acid was significantly positively associated with fasting serum triglyceride, BMI, gender and, in women, the use of oral contraceptives. No other variable was significantly associated with fasting serum uric acid (Table 3). Fasting serum triglyceride was the variable that was most strongly associated with fasting serum uric acid. The importance 
Table 2 Spearman correlation coefficients between fasting serum uric acid and the insulin sensitivity index, glucose effectiveness, glucose disappearance constant, age, gender, $\mathrm{BMI}$, waist to hip ratio, $\mathrm{VO}_{2} \mathrm{max}$, blood pressure, fasting plasma glucose, fasting serum triglyceride and creatinine, daily intake of alcohol, smoking, use of oral contraceptives and disposition for NIDDM in the population-based sample of 380 young healthy Danish Caucasians.

\begin{tabular}{|c|c|c|c|c|c|c|}
\hline & \multicolumn{2}{|c|}{ Men $(n=186)$} & \multicolumn{2}{|c|}{ Women $(n=194)$} & \multicolumn{2}{|c|}{ All $(n=380)$} \\
\hline & $r^{2}$ & $P$ & $r^{2}$ & $P$ & $r^{2}$ & $P$ \\
\hline Age & 0.12 & 0.010 & 0.05 & 0.45 & 0.11 & 0.040 \\
\hline BMI & 0.40 & $<0.001$ & 0.24 & 0.001 & 0.37 & $<0.001$ \\
\hline Waist to hip ratio & 0.32 & $<0.001$ & 0.19 & 0.008 & 0.60 & $<0.001$ \\
\hline Systolic blood pressure & 0.10 & 0.17 & 0.10 & 0.18 & 0.41 & $<0.001$ \\
\hline Diastolic blood pressure & 0.33 & $<0.001$ & 0.23 & 0.002 & 0.33 & $<0.001$ \\
\hline $\mathrm{VO}_{2} \max$ & -0.27 & $<0.001$ & -0.22 & 0.003 & 0.04 & 0.45 \\
\hline Alcohol consumption & -0.04 & 0.62 & 0.07 & 0.34 & 0.23 & $<0.001$ \\
\hline Smoking & 0.09 & 0.22 & -0.10 & 0.17 & -0.05 & 0.29 \\
\hline Use of oral contraceptives & - & - & -0.12 & 0.11 & - & - \\
\hline Fasting serum triglyceride & 0.39 & $<0.001$ & 0.15 & 0.037 & 0.32 & $<0.001$ \\
\hline Fasting plasma glucose & 0.16 & 0.032 & -0.04 & 0.58 & 0.29 & $<0.001$ \\
\hline Fasting serum creatinine & 0.15 & 0.042 & -0.00 & 0.97 & 0.36 & $<0.001$ \\
\hline Disposition for NIDDM & -0.08 & 0.28 & -0.08 & 0.28 & -0.04 & 0.40 \\
\hline Insulin sensitivity index & -0.25 & 0.001 & -0.25 & $<0.001$ & -0.17 & 0.001 \\
\hline Glucose effectiveness & -0.04 & 0.62 & -0.02 & 0.80 & -0.19 & $<0.001$ \\
\hline Glucose disappearance constant & 0.07 & 0.37 & -0.03 & 0.65 & -0.11 & $<0.001$ \\
\hline
\end{tabular}

of gender is seen by the fact that the explained variation, $r^{2}$, in the fasting serum uric acid level in the multiple regression analyses stratified for gender was $24 \%$ in men and $17 \%$ in women but $51 \%$ in the multiple regression analysis including both men and women. The genderstratified multiple regression analyses gave the same results in men and women, and especially we found no significant association between fasting serum uric acid and the insulin sensitivity index in either men or women.

\section{Discussion}

Hyperuricaemia is commonly associated with obesity, glucose intolerance, dyslipidaemia and coronary artery disease (14-16). It has therefore been argued that elevated fasting serum uric acid levels might be yet another facet of the insulin resistance syndrome (11, 17-20). This idea has been supported by several epidemiological studies. Thus Modan et al. (11) found in a representative sample of 1016 Jewish subjects aged 37-70 years a highly significant positive correlation between fasting serum uric acid levels and plasma insulin responses (sum of 1- and 2-h post oral glucose levels) in both males and females. Facchini et al. (19) found in 36 glucose-tolerant volunteers aged 23-69 years, independent of age, gender, overall obesity and abdominal obesity, a positive relationship between fasting serum uric acid levels and insulin resistance

Table 3 The relationship between the fasting serum uric acid and the insulin sensitivity index controling age, gender, BMI, waist to hip ratio, $\mathrm{VO}_{2}$ max, fasting serum triglyceride and creatinine, daily intake of alcohol, smoking, use of oral contraceptives, and disposition for NIDDM in the population-based sample of 380 young Caucasians.

\begin{tabular}{|c|c|c|}
\hline & \multicolumn{2}{|l|}{ Response variable: fasting serum uric acid } \\
\hline & Regression coefficients (95\% confidence interval) & $P$ value \\
\hline $\begin{array}{l}\text { Insulin sensitivity index }\left(10^{-5} \times(\mathrm{min} \times \mathrm{pmol} / \mathrm{l})^{-1}\right) \\
\text { Gender }(0=\text { male, } 1=\text { female }) \\
\text { Age (years) } \\
\text { Waist to hip ratio } \\
\mathrm{VO}_{2} \mathrm{max}\left(\mathrm{ml} \mathrm{O}_{2} /(\min \times \mathrm{kg})\right) \\
\text { Alcohol consumption }(\mathrm{g} / \mathrm{day}) \\
\text { Smoking }(0=\text { no, } 1=\text { yes }) \\
\text { Fasting plasma triglyceride }(\mathrm{mmol} / \mathrm{l}) \\
\text { Fasting serum creatinine }(\mu \mathrm{mol} / \mathrm{l}) \\
\text { BMI }\left(\mathrm{kg} / \mathrm{m}^{2}\right) \\
\text { Disposition for NIDDM }(0=\mathrm{no}, 1=\text { yes }) \\
\text { Use of oral contraceptives }(0=\mathrm{no}, 1=\text { yes }) \\
\left.r^{2} \text { (adjusted }\right)=0.51\end{array}$ & $\begin{array}{l}-3.7 \times 10^{-2}(-10.6-3.1) \\
-7.1 \times 10^{-1}(-9.0--5.1) \\
-2.0 \times 10^{-2}(-19.1-15.0) \\
9.0(-4.1-22.0) \\
-3.5 \times 10^{-2}(-11.4-4.3) \\
3.2 \times 10^{-1}(-56.6-63.0) \\
1.3 \times 10^{-1}(-10.7-13.4) \\
2.4(1.4-3.4) \\
3.9 \times 10^{-2}(-0.1-8.7) \\
3.1 \times 10^{-1}(1.0-5.2) \\
-1.4(-3.6-0.7) \\
-2.6(-4.5--0.75)\end{array}$ & $\begin{array}{l}0.29 \\
<0.0001 \\
0.81 \\
0.18 \\
0.38 \\
0.92 \\
0.92 \\
<0.0001 \\
0.11 \\
0.0032 \\
0.18 \\
0.0062\end{array}$ \\
\hline
\end{tabular}


as measured by the insulin suppression test. Also Vuorinen-Markkola \& Yki-Järvinen (17) showed in 37 healthy subjects aged 30-68 years, independent of age and BMI, positive correlations between insulin resistance as determined by the euglycaemic, hyperinsulinaemic clamp technique and fasting levels of serum uric acid. Furthermore, in a study of 40 healthy males Zavaroni et al. (18) reported that subjects with asymptomatic hyperuricaemia had a higher blood pressure, when matched for age and overall obesity and were more hyperinsulinaemic and dyslipidaemic compared with a group of volunteers with normal serum levels of uric acid. Finally, Cigolini et al. (20) demonstrated in a random sample $(n=181)$ of 38 -year-old healthy and non-obese subjects that both abdominal fat distribution and hypertriglyceridaemia, rather than fasting hyperinsulinaemia, play a major role in the relationship between hyperuricaemia and other components of the insulin resistance syndrome.

In a population-based sample of 380 young healthy individuals we have examined the associations between fasting serum uric acid on the one hand and the insulin sensitivity index and features of the insulin resistance syndrome on the other hand. Methodologically, the importance of stratifying the sample by gender in the univariate analysis is shown by the fact that very different strengths of correlations are found when the sample is either analysed as a whole or stratified by gender. Fasting serum triglyceride, BMI, use of oral contraceptives and gender were the only variables which were independently associated with fasting serum uric acid in the multiple regression analysis.

Some unmeasured factor related to gender must be a major determinant of fasting serum values of uric acid as gender is a major determinant of fasting serum uric acid. In another population based study by Cigolini et al. (20) fasting serum triglyceride was also independently associated with fasting serum uric acid. In contrast, however, the estimate of abdominal distribution of fat in men was not a major determinant of fasting serum uric acid in our study. This may be explained by the lower waist to hip ratio in the present study compared with the study by Cigolini (20) (0.86 versus 0.96 ). The lack of subjects with a high amount of abdominal fat diminishes the effect of abdominal fat on fasting serum uric acid levels. Sinagra et al. (33) also found insulin sensitivity to be independently associated with fasting serum uric acid in a case-control study comparing non-hyperuricaemic and hyperuricaemic obese female subjects. As in our study, Vuorinen-Markkola \& Yki-Järvinen (17) found that fasting serum uric acid was associated with both fasting serum triglyceride and insulin sensitivity in the univariate analysis. In contrast with our study, fasting serum uric acid was independently associated with fasting serum values of triglyceride and insulin sensitivity in the multiple regression analysis. The strength of the association between fasting serum uric acid and the insulin sensitivity index was, however, relatively weak $(P<0.05)$ whereas the association with triglyceride was stronger $(P<0.005)(17)$.

One reason for the weaker association found in our study between insulin sensitivity and fasting serum uric acid compared with the studies of others $(17,19)$ could be the different methodology applied for measuring insulin sensitivity, as the use of the 12 samples minimal model technique gives less accurate estimate of insulin sensitivity than the glucose clamp technique. Another reason for the weaker association between insulin sensitivity and fasting serum uric acid found in our study could be that the range for the serum level of uric acid is relatively narrow, as the examined subjects are young and healthy. In the study by Modan et al. (11) fasting triglyceridaemia was of minor importance compared with the insulin response after an oral glucose tolerance test. The overall explained variation, however, was lower compared with our study (17 versus $51 \%$ ), which may be related to the fact that the study participants were not representative of the general population and the insulin response after an oral glucose tolerance test is a poor measure of insulin sensitivity.

It has been suggested that the positive association between the insulin resistance syndrome and fasting hyperuricaemia is partly explained by the fact that hyperinsulinaemia may decrease the renal excretion of uric acid $(19,34)$. In our study, the association between fasting serum values of uric acid and creatinine did not reach statistical significance. Previously, fasting serum values of uric acid and creatinine have been shown to be positively associated in a population-based study (35), where no measurements of fasting serum triglyceride or the insulin sensitivity index were undertaken.

Serum uric acid is likely to be determined by both genetic and environmental factors $(35,36)$. The potential mechanisms relating fasting hyperuricaemia to fasting hypertriglyceridaemia are unknown. Moreover, why is the insulin sensitivity index and the fasting serum uric acid level more strongly associated in the univariate analysis than in the multivariate analysis? Obesity, waist to hip ratio, BMI and fasting serum triglyceride are all reported to be important determinants of fasting serum uric acid (12), and thus it has been speculated that the positive association between fasting serum values of uric acid and triglyceride could be due to an increase in NADPH requirement for de novo fatty acid synthesis in obese man (17). When NADPH production is increased, then an enhanced uric acid production is the result, and this might increase the serum uric acid level (17). Fasting serum triglyceride and obesity are inherent parts of the insulin resistance syndrome (35). Therefore, the association between the fasting serum uric acid level and the insulin sensitivity index may be secondary to the association with BMI and hypertriglyceridaemia.

In conclusion, we have found that the most important determinant of the fasting serum uric acid 
level in young healthy Caucasians is the fasting serum triglyceride level. Therefore, by its association to hypertriglyceridaemia, hyperuricaemia appears to be a feature of the insulin resistance syndrome.

\section{Acknowledgements}

The study was supported by grants from the University of Copenhagen, the Danish Diabetes Association, the Danish Heart Foundation, the Danish Hospital Foundation for Medical Research, Region of Copenhagen, the Faeroe Islands and Greenland, the Else and Mogens Wedell-Wedellsborg Foundation, Bristol-Myers Squibb, Frimodt-Heineke Foundation, House of Prince, Novo's Foundation, Ingeniør August Frederik Wedell Erichsens Foundation, Grosser A V Lykfeldts og Hustrus Foundation Legat, Foundation of 1870 and Leo Chemicals. The authors thank Kia Olsen, Mette Sadolin, Lone Westh, Miguel Lee, Birgitte Stumann, Karen Grunnet, Annemette Forman, Lene Aabo, Bente Mottlau, Susanne Kjellberg, Jane Brønnum and Quan Truong for excellent technical assistance.

\section{References}

1 DeFronzo RA \& Ferrannini E. Insulin resistance. A multifaceted syndrome responsible for NIDDM, obesity, hypertension, dyslipidaemia, and atherosclerotic cardiovascular disease. Diabetes Care 199114 173-194.

2 Fontbonne A, Charles MA, Thibult N, Richard JL, Clause JR, Warnet JM et al. Hyperinsulinaemia as a predictor of coronary heart disease mortality in a healthy population: the Paris Prospective Study, 15-year follow-up. Diabetologia 199134 356-361.

3 Pyöräla K, Savolainen E, Kaukola S \& Haapakoski J. Plasma insulin as coronary heart disease risk factor: relationship to other risk factors and predictive value during 91/2-year follow-up of the Helsinki policemen study population. Acta Medica Scandinavica 1985701 (Suppl) 38-52.

4 Welborn TA \& Wearne K. Coronary heart disease incidence and cardiovascular mortality in Busselton with reference to glucose and insulin concentrations. Diabetes Care 19792 154-160.

5 Ferrara A, Barrat-Connor EL \& Edelstein Sl. Hyperinsulinaemia does not increase the risk of fatal cardiovascular disease in elderly men or women without diabetes: the Rancho Bernado Study 1984-1991. American Journal of Epidemiology $199410857-869$.

6 Hargreaves AD, Logan RL, Elton RA, Buchanan KD, Oliver MF \& Rimersma RA. Glucose tolerance, plasma insulin, HDL cholesterol and obesity: 12-year follow-up and development of coronary heart disease in Edinburgh men. Atherosclerosis 199294 61-69.

7 Orchard TJ, Eichner J, Kuller LH, Becker DJ, McCallum LM \& Grandits GA. Insulin as a predictor of coronary heart disease: interaction with apoprotein E phenotype. A report from the Multiple Risk Factor Intervention Trial. American Journal of Epidemiology 1983118 326-337.

8 Yarnell JWG, Sweetnam PM, Marks V, Teale JD \& Bolton CH. Insulin in ischaemic heart disease: are associations explained by triglyceride concentrations? The Caerphilly prospective study. Annals of Epidemiology 19944 40-45.

9 Welin L, Eriksson H, Larsson B, Ohlson LO, Svärdsudd K \& Tibblin G. Hyperinsulinaemia is not a major coronary risk factor in elderly men. The study of men born in 1913. Diabetologia 1992 35 766-770.

10 Denis G \& Laumay MP. Preliminary Report. Carbohydrate intolerance in gout. Metabolism 196918 770-775.
11 Modan M, Halkin K, Karasik A \& Lusky A. Elevated serum uric acid - a facet of hyperinsulinaemia. Diabetologia $198730713-$ 718.

12 Yano K, Rhoads GG \& Kagan A. Epidemiology of serum uric acid among 8000 Japanese-American men in Hawaii. Journal of Chronic Diseases $197730171-184$.

13 Saggiani F, Pilati S, Targher G, Branzi P, Muggeo M \& Bonora E. Serum uric acid and related factors in 500 hospitalized subjects. Metabolism 199645 1557-1561.

14 Bengtsson C, Lapidus L, Stedahal C \& Waldenström J. Hyperuricaemia and risk of cardiovascular disease and overall death: a 12year follow-up of participants in the population of study of women in Gothenburg, Sweden. Acta Medica Scandinavica 1988224 549-555.

15 Brand FE, McGee DL, Kannel WB, Stokes III J \& Castelli WP. Hyperuricaemia as a risk factor of coronary heart disease: the Framingham Study. American Journal of Epidemiology 1985121 $11-18$.

16 Klein R, Klein BE, Coroni JC, Maready J, Cassel JC \& Tyroler HA. Serum uric acid: its relationship to coronary heart disease risk factors and cardiovascular disease, Evans County, Georgia. Archives of Internal Medicine 1973132 401-410.

17 Vuorinen-Markkola H \& Yki-Järvinen H. Hyperuricaemia and insulin resistance. Journal of Clinical Endocrinology and Metabolism $19947825-28$.

18 Zavaroni I, Mazz S, Fantuzzi M, Dall'Oglio E, Bonara E, Delsignore $\mathrm{R}$ et al. Changes in insulin and lipid metabolism in males with asymptomatic hyperuricaemia. Journal of Internal Medicine 1993134 25-30.

19 Facchini F, Chen I, Hollenbeck CB \& Reaven GM. Relationship between resistance to insulin-mediated glucose uptake, urinary uric acid clearance, and plasma uric acid concentration. Journal of the American Medical Association 1991266 3008-3011.

20 Cigolini M, Targher G, Tonoli M, Manara F, Muggeo M \& De Sandre G. Hyperuricaemia: relationships to body fat distribution and other components of the insulin resistance syndrome in 38-yearold healthy men and women. International Journal of Obesity 1995 $1992-96$.

21 Ibsen KK. Blood pressure in Danish children and adolescents. Acta Paediatrica Scandinavica $19917027-31$.

22 Clausen JO, Hansen T, Bjørbæk C, Echwald SM, Urhammer SA, Rasmussen $\mathrm{S}$ et al. Insulin resistance: interactions between obesity and a common variant of insulin receptor substrate-1. Lancet $1995346394-402$.

23 Clausen JO, Ibsen H, Borch-Johnsen K, Bergman RN, Hougaard P, Winther $\mathrm{K}$ et al. Insulin sensitivity index, acute insulin response and glucose effectiveness in a population-based sample of 380 young healthy caucasians: analysis of the impact of gender, body fat, physical fitness and life style factors. Journal of Clinical Investigation 199698 1195-1209.

24 Åstrand PO \& Ryhning I. A nomogram for calculation of aerobic capacity (physical fitness) from pulse rate during submaximal work. Journal of Applied Physiology 19547 218-221.

25 Rose G \& Blackburn H. Cardiovascular Survey Methods. World Health Organization Monograph Series, 56. Geneva: World Health Organization, 1968.

26 Andersen L, Dinesen B, Jørgensen PN, Poulsen F \& Røder ME. Enzyme immunoassay for intact insulin in serum and plasma. Clinical Chemistry $199339578-582$.

27 Pacini G \& Bergman RN. MINIMOD: a computer program to calculate SI and pancreatic responsivity from the frequently sampled intravenous glucose tolerance test. Computer Methods and Programs in Biomedicine 198623 113-122.

28 Steil GM, Vølund AA, Kahn SE \& Bergman RN. Reduced sample number for calculation of insulin sensitivity and glucose effectiveness from the minimal model. Suitability for use in population studies. Diabetes 199342 250-256.

29 Steil GM, Murray J, Bergman RN \& Buchanan TA. Repeatability of insulin sensitivity and glucose effectiveness from the minimal model. Diabetes 199443 1365-1371. 
30 Ferrari P, Alleman Y, Shaw S, Reisen W \& Weidmann P. Reproducibility of insulin sensitivity measured by the minimal method. Diabetologia 199134 527-530.

31 Bergman RN, Prager R, Vølund AA \& Olefsky JM. Equivalence of the insulin-sensitivity index in man derived by the minimal model method and the euglycemic glucose clamp. Journal of Clinical Investigation $1987679790-800$.

32 Beard JC, Bergman RN, Ward WK \& Porte D Jr. The insulin sensitivity index in nondiabetic man: correlation between clampderived and IVGTT-derived values. Diabetes $198635362-369$.

33 Sinagra D, Greci D, Scarpitta AM \& Bonaventura V. Serum uric acid, insulin secretion and resistance in nonhyperuricemic and hyperuricemic obese female subjects. International Journal of Obesity 199620 1041-1043.
34 Galvan AQ, Natali A, Baldi S, Frascerra S, Sanna G, Ciociaro D et al. Effect of insulin on uric acid excretion in humans. American Journal of Physiology (Endocrinology and Metabolism) 199531 E1-E5.

35 Tuomilehto J, Zimmet P, Wolf E, Taylor R, Ram P \& King H. Plasma uric acid level and its association with diabetes mellitus and some biological parameters in a biracial population of Fiji. American Journal of Epidemiology 1988127 321-336.

36 Mikkelsen WM, Dodge HJ \& Valkenburg H. The distribution of serum uric acid values in a population unselected as to gout or hyperuricaemia. American Journal of Medicine 196539 242-251.

Received 13 February 1997

Accepted 30 June 1997 